\title{
An interdisciplinary experience on the development of Dye-Cell technology
}

\author{
Christian Graziani Garcia ${ }^{\dagger}$ and Neyde Yukie Murakami Iha ${ }^{\ddagger}$ \\ Instituto de Química, Universidade de São Paulo (IQ-USP), Av. Prof. Lineu Prestes, 748 - 05508-900, \\ São Paulo - SP, Brazil
}

\begin{abstract}
Under a special program supported by the University of São Paulo (USP) for the development of strategic fields of research, interdisciplinar discussion on the development of photovoltaics and energy technology has been established. Several aspects concerned to solar energy and PV technology were discussed in regular meetings along a year by professionals of different domains. As a result of the program, a collaborative work on the deposition of $\mathrm{TiO}_{2}$ films employed in photoelectrochemical solar cells has been established between the Laboratory of Inorganic Photochemistry and Energy Conversion at the IQ-USP and other research groups.

Preparation of $\mathrm{TiO}_{2}$ emulsions from distinct methods were performed and compared. Spin-coating and painting techniques have been employed for the deposition of $\mathrm{TiO}_{2}$ films over TCO substrates. Both techniques resulted in transparent homogeneous $\mathrm{TiO}_{2}$ films which were successfully used as dye-sensitized photoanodes in solar cells. The results show that thin-film properties, such as thickness and transparency, can be controlled through the deposition technique and that photoelectrochemical measurements carried out by our group have been performed under appropriate film deposition conditions.

This experience shows also that different institutions, with distinct purposes, can interact and work together to prepare qualified professionals for many areas of modern science and technology.
\end{abstract}

\section{INTRODUCTION}

Although ascendant, the development of photovoltaic solar energy in Brazil is considerably recent and its contribution as an alternate energy source is incipient. Due to its geographic characteristics, large territorial area, favorable tropical climate and the existence of several remote communities not provided by electrical energy network, photovoltaics is the most feasible alternative, when the environmental and the resources conservation are considered, to the ascending Brazilian energy needs.

Renewable energy conversion has long been of major interest in both academic and productive fields. Having this aim as the main purpose, an interdisciplinary program between distinct institutions was established to discuss subjects on the development of photovoltaics and solar energy technology under a CIUPE program $\left({ }^{1}\right)$ (Inter-institutional Collaborative Program for Strategic Researches), supported by the University of São Paulo. This interaction also stimulated a cooperative work between the Laboratory of Inorganic Photochemistry and Energy Conversion of the Chemistry Institute USP and the Laboratory of Microelectronics $(L M E)\left({ }^{2}\right)$ of

\footnotetext{
† E-mail: cggarcia@iq.usp.br

‡ E-mail: neydeiha@iq.usp.br

$\left({ }^{1}\right)$ CIUPE Program - Development of Energy Conversion Systems: N. Y. Murakami Iha (coordinator), C. G. Garcia, M. K. Itokazu, A. N. Geraldes, A. S. Polo, D. L. A. Faria, A. M. Andrade, F. J. Fonseca, E. A. T. Dirani, A. A. Batista, M. O. Santiago, F. B. C. Machado and C. A. Bignozzi.

${ }^{2}$ ) LME - Escola Politécnica, Fernando J. Fonseca, Ely A. T. Dirani and Adnei M. Andrade, Universidade de São Paulo - USP, São Paulo - SP, Brazil.
}

the Polytechnic School - USP on the deposition of $\mathrm{TiO}_{2}$ films employed in photoelectrochemical solar cells.

Investigation on dye-sensitized photoelectrochemical solar cells has experienced remarkable progress since the development of porous nanometric $\mathrm{TiO}_{2}$ films with a large surface area [1-4]. Such cells have acquired increasing recognition as a promising alternative to traditional silicon-based solar cells [5, 6].

We have been investigating and developing regenerative thin-layer solar cells based on the dye sensitization of nanocrystalline $n$ - $\mathrm{TiO}_{2}$ [7-10]. In this work, preparation of $\mathrm{TiO}_{2}$ emulsions from distinct methods were performed and compared. Spin-coating and painting techniques were employed for the deposition of $\mathrm{TiO}_{2}$ films over TCO substrates in order to establish optimized deposition parameters.

\section{EXPERIMENTAL}

2.1. Materials. All materials were used as supplied without further purification. All chemicals were reagent grade or of the best available purity. Nanopure water was always used.

2.2. Preparation of $\boldsymbol{n}-\mathrm{TiO}_{2}$ emulsions. Two distinct preparations of $\mathrm{TiO}_{2}$ emulsions were performed after modifications of the procedures described in the literature [2, 11]. $12 \mathrm{~g}$ of commercial $\mathrm{TiO}_{2}$ (Degussa P25) were ground in porcelain mortar with $6 \mathrm{~mL}$ of water containing $0.4 \mathrm{~mL}$ of acetylacetone (Aldrich 99\%). $14 \mathrm{~mL}$ of water and $0.2 \mathrm{~mL}$ of Triton X-100 (Aldrich) were slowly added to the mixture under continuous grinding for $10 \mathrm{~min}$. Alternatively, $25 \mathrm{~mL}$ of titanium isopropox- 
ide $99.999 \%$ (Aldrich) are added dropwise to an aqueous nitric acid solution (65\%). After 8 hours at $80^{\circ} \mathrm{C}$ under continuous stirring the solution is autoclaved at $200^{\circ} \mathrm{C}$ for $15 \mathrm{~h} .0 .6 \mathrm{~g}$ of Carbowax 2000 (Aldrich) is added and the mixture is kept under stirring overnight.

2.3. Thin-film deposition. ITO or FTO substrates (Asahi) were carefully cut in $2.5 \mathrm{~cm} \times 3.0 \mathrm{~cm}$ segments and masked with an adhesive tape in order to obtain electrodes with active area of $0.5 \mathrm{~cm}^{2}$. Semiconductor emulsions were homogeneously distributed over the substrates by direct painting or spin coating techniques, as previously described [12]. Alternatively, spin coating was obtained in a SCS model P-6204-A Spin Coater Machine at the LME. Thin films were obtained by painting spreading the semiconductor emulsions over the substrates with a glass rod or glass plate. After drying, oxide semiconductor films were sintered at $450{ }^{\circ} \mathrm{C}$ for $30 \mathrm{~min}$ in an EDG furnace model F-7000-3P.

Thickness measurements of semiconductor-coated substrates were performed using a Coordinate Measuring Machine from Mitutoyo, model BLN112, at GARMA Indústria e Comércio LTDA.

2.4. Thin-layer solar cell. The molecular sensitizers were synthesized following the procedures described in the literature $[7,8]$. The dyes were attached to the $\mathrm{TiO}_{2}$ surface by immersing the processed electrode in $10^{-4} \mathrm{M}$ ethanolic solutions of the corresponding complexes.

Photoelectrochemical experiments were carried out by using the dye-sensitized $\mathrm{TiO}_{2}$ films incorporated into thin-layer sandwich-type solar cells as described in the literature $[7,8]$. The photoanode consists of the $\mathrm{TiO}_{2}$ film sensitized by a molecular sensitizer on a FTO substrate. A transparent Pt-covered TCO substrate is used as a counter electrode. As the redox mediator and electrolyte, 0.05 $\mathrm{M} \mathrm{I}_{2}$ (Merck)/0.5 M LiI (Aldrich) solution in acetonitrile (Aldrich)/3-methyl-2-oxazolidinone (Aldrich), vol. 90/10 was employed.

2.5. Physical measurements. Absorption and transmission spectra were recorded on a Hewlett Packard model 8453 UV-visible spectrophotometer. Preliminary experiments were carried out using an overhead projector as a light source. Photocurrent and voltage measurements were obtained as previously described [7, 8] using an A. W. Sperry digital multimeter, model DM-8A.

\section{DISCUSSION}

3.1. Preparation of semiconductor emulsions and thin film deposition. Figure 1 presents profiles of thin films deposited over glass substrates employing painting and spin-coating techniques, respectively. Semiconductor oxide emulsions were obtained directly from commercial $\mathrm{TiO}_{2}$. Whereas the spin-coating tech- nique results in homogeneous, regular films, painted films show less regular surfaces, associated to imperfections presented by the glass rod employed.

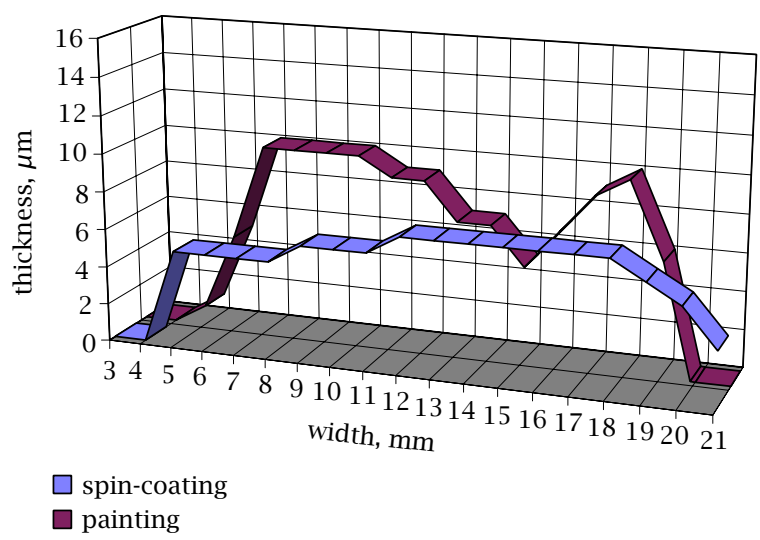

Figure 1. Profile of $\mathrm{TiO}_{2}$ films deposited over glass substrates by painting and spin-coating techniques. Semiconductor oxide emulsions were obtained directly from commercial $\mathrm{TiO}_{2}$.

The average thickness of films obtained directly from commercial $\mathrm{TiO}_{2}$ after five profile evaluation is between 6 and $10 \mu \mathrm{m}$. Semiconductor emulsions obtained by titanium isopropoxide result in thinner and more transparent films, and could not be resolved with the available equipment.

Deposition by spin-coating was also found to be more reproducible and sensitive to experimental conditions. Figure 2 shows transmittance values at $400 \mathrm{~nm}$ obtained for semiconductor films deposited by spincoating as a function of speed rotation. $\mathrm{TiO}_{2}$ emulsions were obtained from the titanium isopropoxide route. It is observed that depositions carried out under faster speed rotations result in thinner, more transpar-

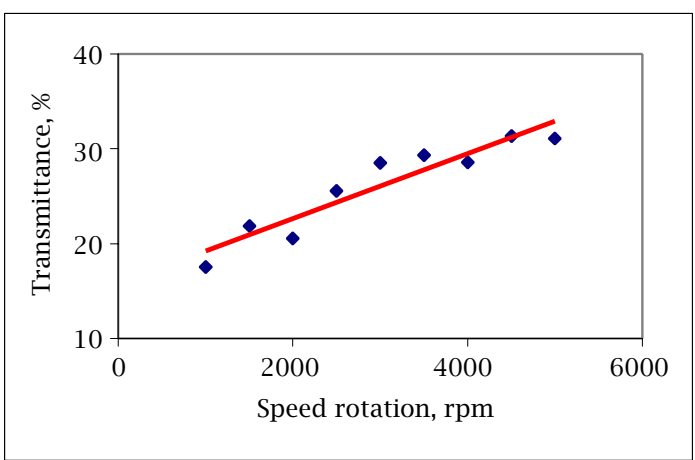

Figure 2. Transmittance at $400 \mathrm{~nm}$ obtained for semiconductor films deposited by spin-coating as a function of speed rotation. Semiconductor oxide emulsions were obtained from the titanium isopropoxide route. 


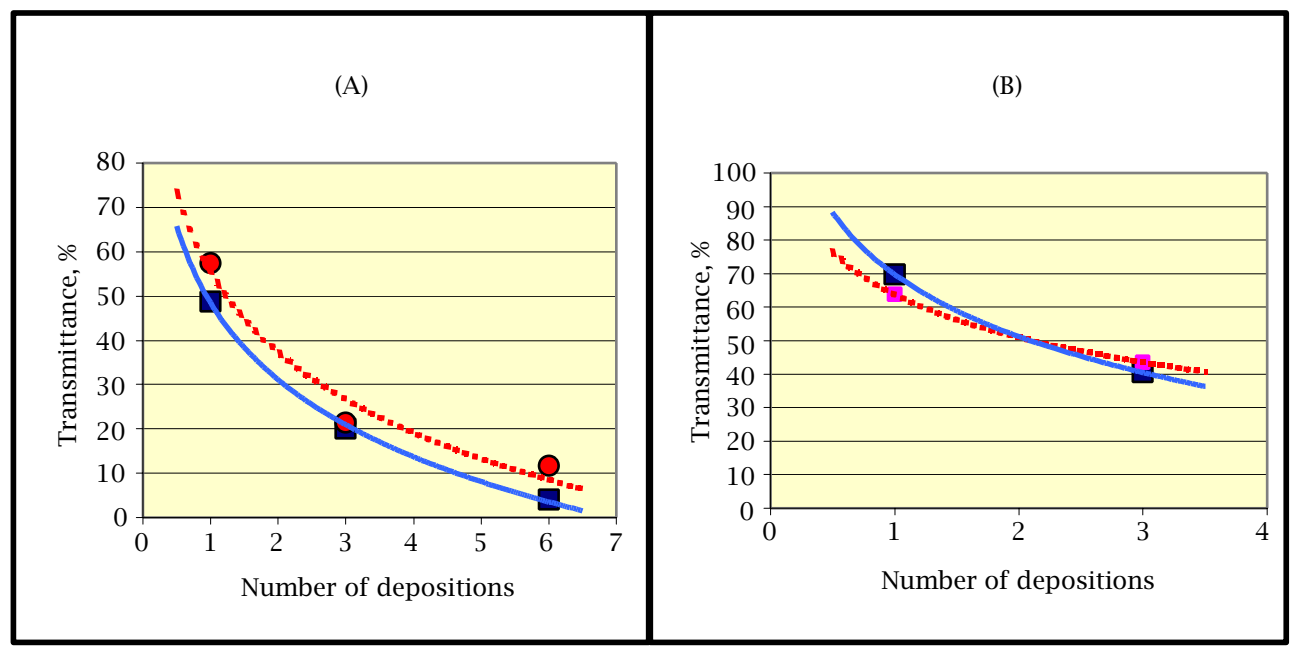

Figure 3. Transmittance at $700 \mathrm{~nm}$ vs. number of depositions by (A) spin-coating and (B) painting: (-) set one and (- - ) set two.

ent films. On the other hand, the painting technique does not provide enough sensitivity and a direct relationship between the painting speed and the resulting film thickness can not be established.

Further experiments were performed in order to evaluate the reproducibility obtained with each deposition technique. Two independent sets of oxide-coated substrates were prepared by both painting and spincoating techniques. Successive depositions were performed in order to obtain films with different thickness. Figure 3 presents the relationship between the number of depositions and the resulting transmittance values at $700 \mathrm{~nm}$ of the consecutively deposited films obtained with spin coating and painting techniques. Film depositions obtained by both techniques were quite reproducible. It can be seen that consecutive depositions result in thicker and less transparent films. Under the experimental conditions, the painting technique provided more transparent and thinner films. Photoanode transparency is an interesting characteristic for the development of thin-layer transparent solar cells to be employed in novel applications.

3.2. Photoelectrochemical measurements. The effect of the deposition mode and resulting $\mathrm{TiO}_{2}$ film thickness is further observed in the photoelectrochemical properties of the assembled cell. Figure 4 presents photocurrent values obtained with solar cells employing photoanodes with distinct, consecutively deposited, oxide films obtained by spin coating and painting techniques. The $\left[\left(\mathrm{dcbH}_{2}\right)_{2} \mathrm{Ru}(\mathrm{SCN})_{2}\right]$ complex was employed as standard sensitizer in all prepared $\mathrm{TiO}_{2}$ films (electrode area $=0.5 \mathrm{~cm}^{2}$ ). The relationship between the number of depositions and the resulting photocurrent values is observed. Under the experimental conditions, thicker films obtained by consecutive depo- sitions resulted in lower photocurrent values. It is also observed that photoanodes obtained by a single oxide deposition result in more resistant films and provide more transparent solar cells, with higher photocurrent generation.

The concentration of the semiconductor emulsion strongly affects the final characteristics of the painted films. Previous results employing photoanodes obtained by a single oxide deposition revealed that thicker films provided higher photocurrent values [13]. A photocurrent increase with the film thickness is expected to occur up to a limit thickness of around $0.75 \mu \mathrm{m}$ after which charge migration across the film becomes unfavorable, limiting the photocurrent generation [14].

3.3. The CIUPE program. The interdisciplinary CIUPE program, supported by our University, promoted the association of professionals of different domains to discuss the development of photovoltaics and energy technology.

Economic, social and technological aspects concerned to solar energy and PV technology were discussed in regular meetings along a year by professionals in chemistry, physics, architecture, engineering as well as entrepreneurs etc. Several Brazilian as well as foreign relevant researchers and specialists were invited to participate in coordinated discussions and seminars. Typically, a seminar presented by a guest was followed by informal discussions with the other participants. The program also promoted field visits to different laboratories belonging to both participants and guests. The resulting contact enabled the participants to become familiar to activities performed by colleagues from distinct institutions and stimulated interunit collaborations in which former experiences, knowhow as well as physical facilities were shared. 


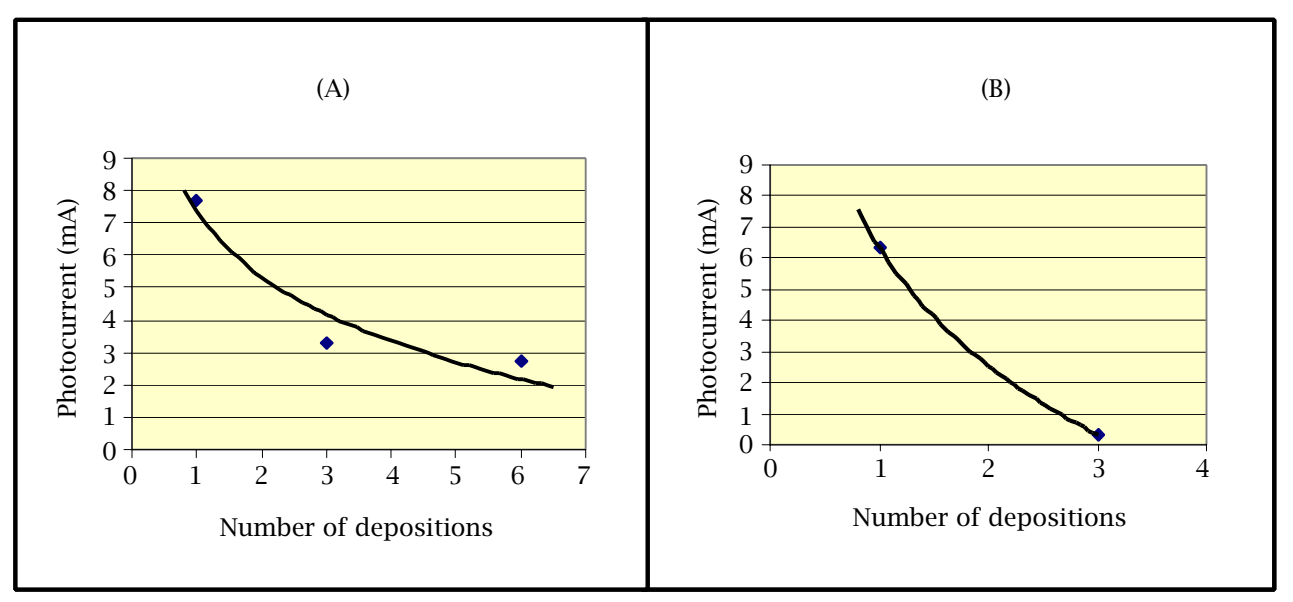

Figure 4. Photocurrent vs. number of depositions obtained by (A) spin-coating and (B) painting.

An updated situation of the Brazilian research on solar energy conversion cells was presented. The establishment of dye-sensitized photoelectrochemical solar cells as an alternative for traditional solid-state solar cells was appointed by Dr. Klaus. P. Hanke from Institute of Applied Photovoltaics, in his talk "Technical Use of Solar Energy - Vision, Option, Reality”.

The participation of governmental entities such as the Secretary of Energy of the State of São Paulo, the Space Research Institute (INPE), and the Reference Center for Eolic and Solar Energy (CRESESB) [15] provided a portrait of former photovoltaics activities performed in our country. Prof. Dr. Thomas J. Meyer, formerly from the University of North Carolina and currently at Los Alamos National Lab., presented two talks entitled "Chemical Approaches to Artificial Photosynthesis" and "Solar Energy: Research in the U.S.," in which different funding sources for solar energy research were presented and discussed. It was frequently mentioned by the participants that the subject did not find the same relevance in Brazil as in other countries, and that a national policy properly directed to stimulate both fundamental and applied research and the use of solar energy systems is necessary.

The participation of GADI (the University's Agency for the Development of Inventions) provided a better understanding of the requirements related to the protection of research results and invents. As an important consequence of the interdisciplinary meetings, the initial contact with GADI has grown up over a year and a half to the preparation of two patent documents involving the work developed at the Laboratory of Inorganic Photochemistry and Energy Conversion.

The relevance of the initiative was confirmed considering the supportive response of different institutions contacted along the period. A proposed national workshop on solar energy conversion organized by this Program with support of CRESESB is programmed to fur- ther establish the inter-institutional effort.

\section{CONCLUSION}

The CIUPE program promoted by University of São Paulo for the development of strategic fields of research enabled a multidisciplinary discussion on the development of photovoltaics and energy technology. As a result of the program, investigations of thin-films have been carried out in a cooperative effort between our Laboratory and other research groups.

Preparation of semiconductor emulsions from titanium isopropoxide or directly from commercial $\mathrm{TiO}_{2}$ were performed and compared. Whereas the preparation of emulsions from Degussa $\mathrm{TiO}_{2}$ is faster and uncomplicated, the isopropoxide hydrolysis method results in thinner, more transparent, semiconductor films. $\mathrm{TiO}_{2}$ oxide films obtained by both methods were employed as semiconductor substrates for molecular sensitizers in thin-layer photoelectrochemical solar cells.

Spin-coating and painting techniques have been employed for the deposition of $\mathrm{TiO}_{2}$ films over TCO substrates. Both techniques resulted in transparent homogeneous $\mathrm{TiO}_{2}$ films which were successfully employed as dye-sensitized photoanodes in the solar cells. Semiconductor film thickness can be increased by performing consecutive independent depositions, but excessive depositions resulted in more fragile $\mathrm{TiO}_{2}$ films. The spin-coating method was found to be more reproducible and sensitive to deposition parameters such as speed rotation and emulsion concentration.

Efficient photoconversion of visible light into electricity has been successfully accomplished with the use of dye-sensitized semiconductor photoanodes. Solar cells with transparent $\mathrm{TiO}_{2}$ films allow the development of novel useful applications such as windows, watches, monitors etc. The results show that thin-film 
properties, such as thickness and transparency, can be controlled and that the photoelectrochemical measurements carried out by our group have been performed under appropriate film deposition conditions.

The interactive experience of collaborative work among different institutions provided both undergraduate and graduate students the opportunity to work towards applied research project.

\section{ACKNOWLEDGEMENTS}

We thank the Conselho Nacional de Desenvolvimento Científico e Tecnológico (CNPq), Fundação de Amparo à Pesquisa do Estado de São Paulo (FAPESP/NUPLITEC) for financial support and Pró-Reitoria de Pesquisa-USP for supporting the CIUPE project.

\section{References}

[1] J. Desilvestro, M. Grätzel, L. Kavan, and J. Moser, J. Am. Chem. Soc. 107 (1985), 2988.

[2] M. K. Nazeeruddin, A. Kay, I. Rodicio, R. HumphryBaker, E. Müller, P. Liska, N. Vlachopoulos, and M. Grätzel, J. Am. Chem. Soc. 115 (1993), 6382.

[3] C. A. Bignozzi, J. R. Schoonover, and F. Scandola, Progr. Inorg. Chem. 44 (1997), 1.

[4] Md. K. Nazeeruddin, P. Péchy, and M. Grätzel, Chem. Commun. 18 (1997), 1705.

[5] Philip Ball, Made to Measure - New Materials for the $21^{\text {st }}$ Century, Princeton University Press, New Jersey, 1997.

[6] L. L. Kazmerski, Renewable and Sustainable Energy Rev. 1 (1997), 77.

[7] C. G. Garcia, N. Y. Murakami Iha, R. Argazzi, and C. A. Bignozzi, J. Bras. Chem. Soc. 9 (1998), 13.

[8] C. G. Garcia, N. Y. Murakami Iha, R. Argazzi, and C. A. Bignozzi, J. Photochem. Photobiol. A: Chem. 115 (1998), 239.

[9] C. G. Garcia, J. F. de Lima, and N. Y. Murakami Iha, Coord. Chem. Rev. 196 (2000), 219.

[10] N. Y. Murakami Iha, Anais Acad. Bras. Ci. 72 (2000), 67.

[11] B. O’Reagan and M. Grätzel, Nature 353 (1991), 737.

[12] M. K. Itokazu, A. K. Nakano, C. G. Garcia, N. Y. Murakami Iha, R. Domingues, N. I. Morimoto, and W. G. Garcia, Film Deposition and Characterization: A Collaborative Work, 2nd International Conference on Industry - Education Co-operation, São Bernardo do Campo, 1997, p. 47.

[13] C. G. Garcia, Células Solares Transparentes Baseadas na Sensibilização de $\mathrm{TiO}_{2}$ por Bipiridinas Carboxiladas de Rutênio(II) com Isoquinolina e 4-Fenilpiridina, Master dissertation, Instituto de Química, Universidade de São Paulo, 1998.

[14] I. Bedja, S. Hotchandani, and P. V. Kamat, J. Phys. Chem. 98 (1994), 4133.

[15] http://www.cresesb.cepel.br 


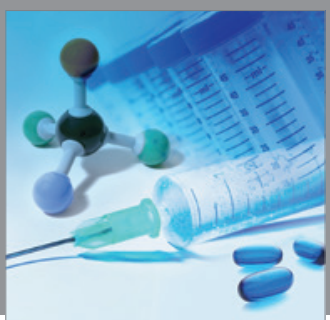

International Journal of

Medicinal Chemistry

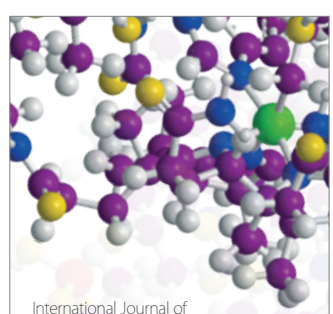

Carbohydrate Chemistry

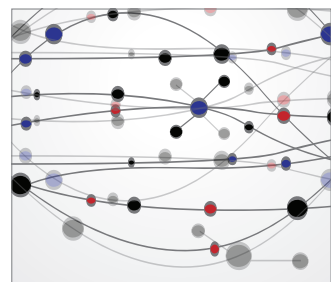

The Scientific World Journal
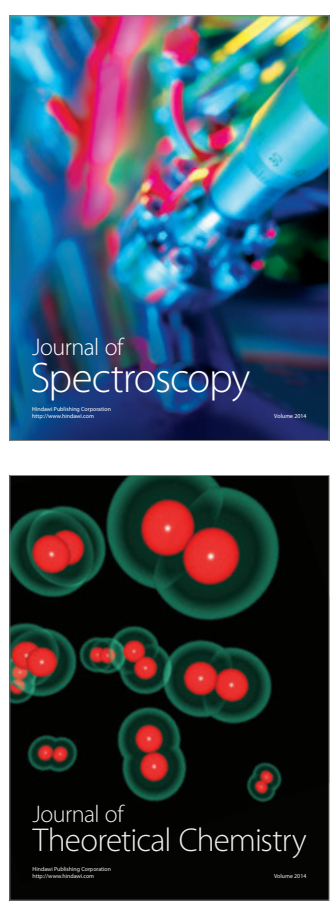
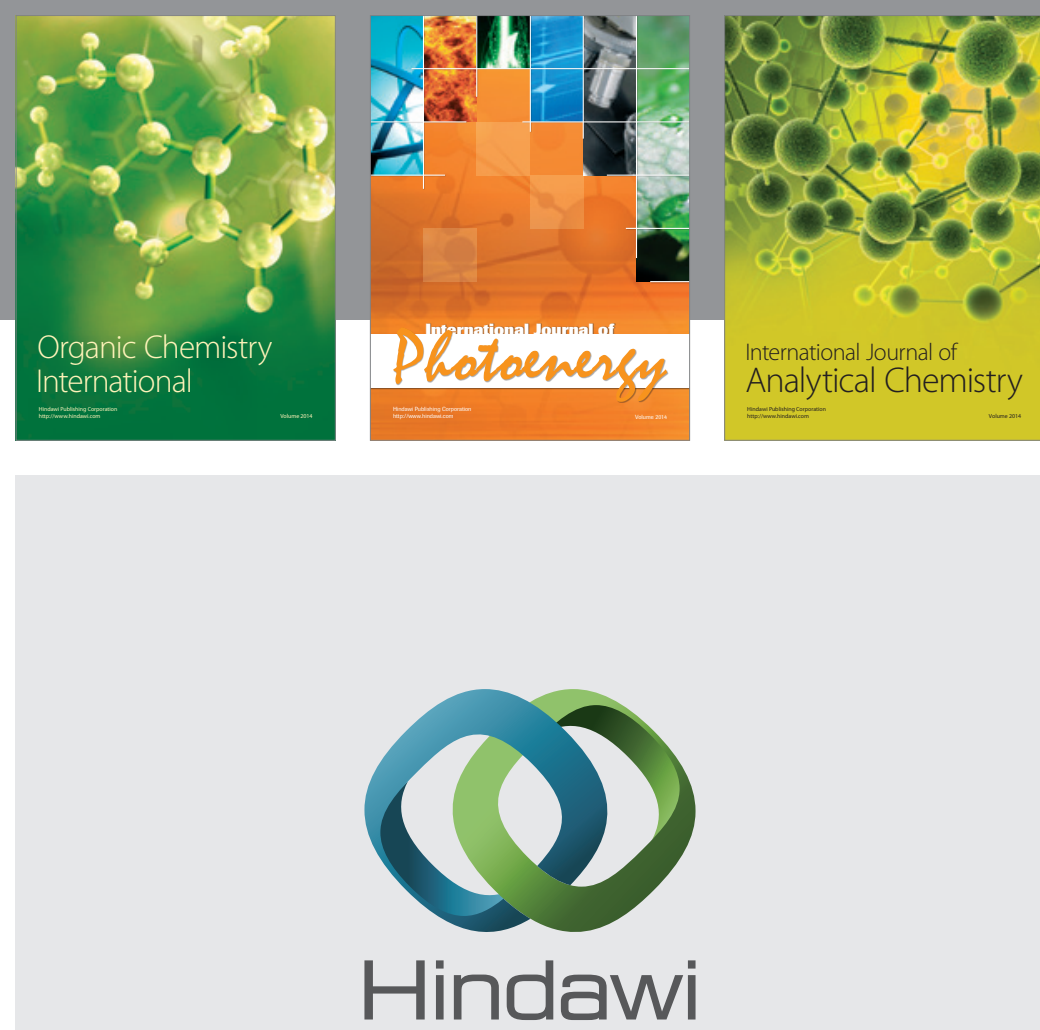

Submit your manuscripts at

http://www.hindawi.com
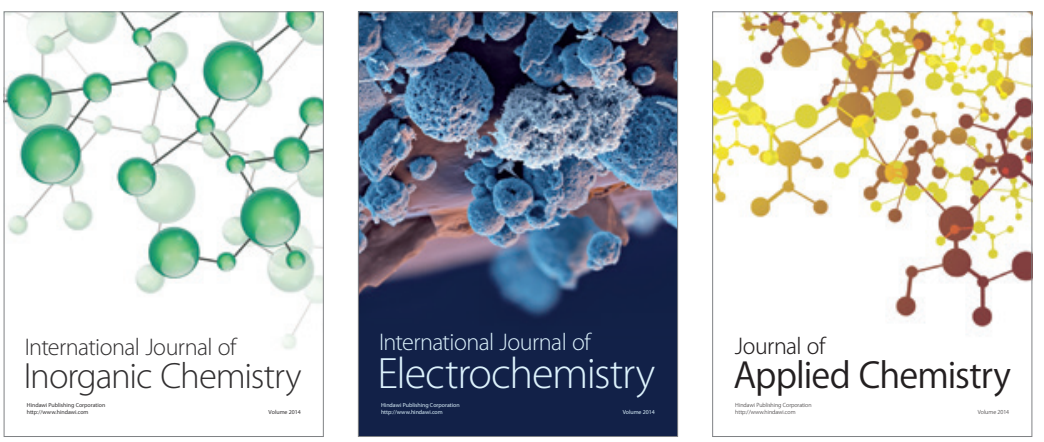

Journal of

Applied Chemistry
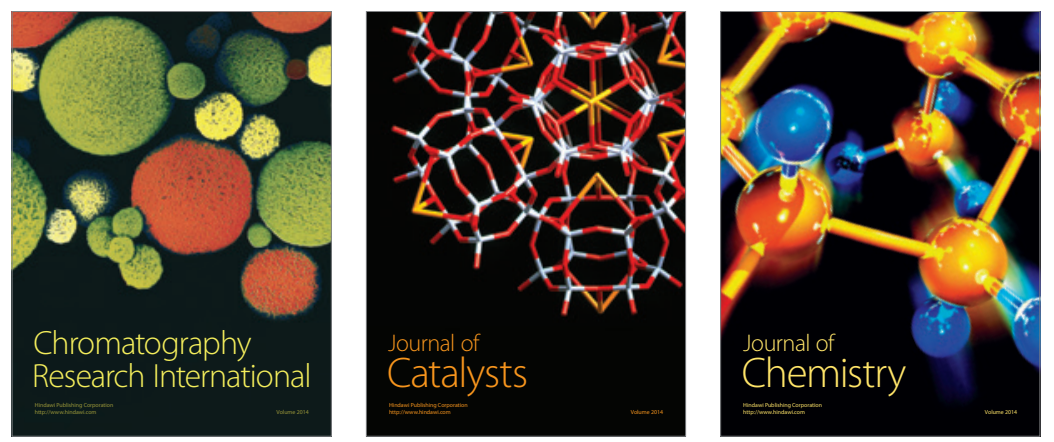
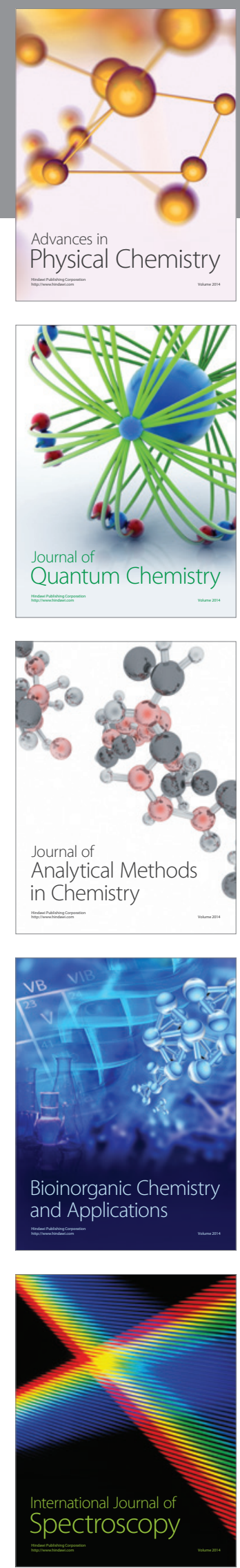